\title{
La argamasa que une los reinos: gestión e integración de las Indias en la Monarquía Hispánica, siglo XVII*/
}

\author{
The Mortar that Keeps the Kingdoms Together: \\ Management and Integration of the Indies \\ in the Hispanic Monarchy, 17th Century
}

\author{
Pilar Ponce Leiva
}

ORCID iD: http://orcid.org/0000-0002-9647-7238

Universidad Complutense de Madrid

\begin{abstract}
A partir del símil que considera la administración como una especie de argamasa capaz de mantener unidos los diferentes reinos integrados en la Monarquía Hispánica, el presente texto centra su atención en la judicatura indiana. Una vez analizadas la naturale$z$ a, las vías de acceso y los ámbitos de acción de los agentes de justicia, se plantean algunas consideraciones en relación al debate sostenido durante el siglo XVII sobre la posición que las Indias ocupaban, o debían ocupar, en el universo contemplado.
\end{abstract}

Palabras Clave: Nombramientos; Criollos; Integración; Agregación; Judicatura; Audiencia; Consejo de Indias; Siglo XVII.

Considering the administration as a mortar that united the different kingdoms integrated in the Hispanic monarchy, this text focuses on the Indies judiciary. Once the nature, the way to access and the remit of the agents of justice is analysed, the text contemplates some considerations in relation to the debate held during the 17th Century about the position the Indies occupied, or should occupy, in that universe.

KeYwords: Appointments; Creoles; Integration; Aggregation; Judiciary; Court; Council of Indies; 17th Century.

Copyright: (C) 2017 CSIC. Este es un artículo de acceso abierto distribuido bajo los términos de una licencia de uso y distribución Creative Commons Attribution (CC-by) España 3.0.

* Este texto se ha elaborado en el marco del Proyecto de Investigación I+D Entre venalidad y corrupción en la Monarquía Hispánica durante el Antiguo Régimen [HAR2014-55305-P], financiado por el Ministerio de Economía y Competitividad de España. 


\title{
Introducción
}

\begin{abstract}
Al hilo de la revisión que se está llevando a cabo sobre la naturaleza de la Monarquía Hispánica, sobre sus mecanismos de integración y de pervivencia, se ha planteado la consideración de que el vasto conglomerado de territorios que la integraban pudo mantenerse unido durante más de 300 años en buena medida gracias a la circulación de un contingente de personas, objetos e ideas que, al desplazarse de un punto a otro del imperio, dieron cohesión y solidez a una construcción que en diversos momentos y por diferentes factores podría haberse disgregado en múltiples unidades. ${ }^{1}$ Una parte esencial de ese conglomerado fueron los agentes de la administración civil y eclesiástica, como gestores de la negociación o el conflicto sobre los que se asentaba el ejercicio del gobierno y como «sólidos lazos humanos» a través de los cuales los Austrias mantuvieron sus territorios en conexión. ${ }^{2}$

Esa consideración de la administración como argamasa que unía los reinos es la cuestión que se pretende revisar a continuación. Se trata de analizar de qué materiales estaba compuesta tal argamasa, cómo y por dónde circularon esos agentes y qué problemas ocasionó la falta de determinados ingredientes. Para ello, se analizarán tres aspectos relacionados con la gestión de las Indias: el primero se sitúa en la metrópoli y se refiere al ingreso en el Consejo de Indias de magistrados con experiencia americana, el segundo se refiere a la circulación de magistrados (presidentes, oidores y fiscales) por las diferentes audiencias indianas y el tercero se desarrolla entre la España peninsular y América y atañe a la participación de americanos en la alta administración de justicia. Una vez analizadas la naturaleza, las vías de acceso y los ámbitos de acción de esos agentes, se plantearán algunas consideraciones en relación al debate sostenido durante el siglo XVII sobre la posición que las Indias ocupaban, o debían ocupar, en el amplio universo que integraba la Monarquía Hispánica.
\end{abstract}

\section{La experiencia como mérito en el Consejo de Indias}

La estabilidad y continuidad institucional que tuvo el Consejo de Indias a lo largo de los siglos no impidió que se desarrollaran en su seno proyectos de reforma y cambios que, en determinadas épocas, supusieron una profunda

\footnotetext{
1 Mazín Gómez y Ruiz Ibáñez, 2012, 10.

2 Soria, 2012. Sobre los oficiales como «sólidos lazos humanos», véase Köenigsberger, 1951, citado por Gil Pujol, 2012, 86.
} 
modificación de sus competencias. Durante el siglo XVII, de forma recurrente cada 20 o 25 años llegaba al Consejo un decreto cuyo objetivo era introducir modificaciones bien en su composición, bien en su funcionamiento interno, bien en ambas cuestiones. ${ }^{3}$ Un aspecto mucho más interesante que los vaivenes en la planta del Consejo son los diversos intentos llevados a cabo para cambiar la composición cualitativa de sus miembros, más concretamente la polémica largamente sostenida sobre el nombramiento de letrados con experiencia americana. Cabe aclarar que, de momento, no estamos hablando de consejeros americanos, sino de individuos con experiencia en asuntos relativos a América por haber servido en ella.

Prácticamente todos los virreyes en sus memorias de gobierno hicieron referencia a la importancia de tener experiencia y conocimiento de las realidades americanas antes de tomar decisiones. Este requisito era esencial en los agentes que pasaban desde la península u otros reinos europeos, pero también aquellos que eran trasladados desde Nueva España a Perú requerían un tiempo de entrenamiento; en palabras del marqués de Montesclaros escritas en Perú en 1615: «aun los que venimos por el rodeo de Nueva España, extrañamos su lenguaje, y nos es preciso, o vivir tartamudos los primeros años, o preguntar desautorizadamente algunas menudencias, que sólo sirven de cimbria al edificio y máquina principal». ${ }^{4}$ De ahí que el marqués de Guadalcázar recomendara a su sucesor en 1628 obrar con cautela, evitando introducir novedades «hasta que, teniendo mayor experiencia de todo, vaya consultando a S. M. lo que se ofreciere en esta razón [...] para lo cual es menester larga experiencia de las cosas de las Indias, y cuando se viene a tener es tiempo de salir de ellas». ${ }^{5}$ Dando un paso más allá, el príncipe de Esquilache en 1621 atribuyó a la falta de conocimiento preciso de las realidades americanas algunas órdenes - a su juicio equivocadas - enviadas desde la metrópoli, limitándose a callar ante ellas y esperar el desarrollo de los acontecimientos, justificando tal actitud al decir «no repliqué a este mandato, porque la experiencia y el tiempo lo harán». ${ }^{6}$

3 Expediente sobre el establecimiento y extinción de la Cámara de Indias, Madrid, 1600-1644; Decreto de reforma del Consejo, Madrid, 6 de julio de 1677; Decreto sobre la forma en que se ha de ejecutar y observar la reforma de los ministros de los consejos, Madrid, 31 de enero de 1687; Decreto de reforma del Consejo de Indias, Madrid, 17 de julio de 1691; Decreto de reforma del Consejo de Indias, Madrid, 6 de marzo de 1701. Todos ellos en: Archivo General de Indias (AGI), Indiferente General, 827. $1921,141$.

4 Relación de Juan de Mendoza y Luna, marqués de Montesclaros, 1615, en Beltrán y Rózpide, 1930, 13.

5 Relación de Diego Fernández de Córdova, marqués de Guadalcázar, 1628, en Altolaguirre,

6 Relación de Francisco de Borja y Aragón, príncipe de Esquilache, 1621, en Beltrán y Rózpide, 1921, 241. 
Fue esta una cuestión de largo recorrido en la literatura sobre el gobierno americano, siendo tratada en numerosos memoriales y consultas del Consejo de Indias durante el siglo XVII. Un memorial anónimo de principios de esa centuria resumió puntualmente las ventajas que podía tener el recurrir a los magistrados con experiencia para cubrir las plazas del Consejo - competencia que en el caso de las Indias correspondía a la Cámara de Castilla—, como se hacía en los casos de Portugal, Italia y Aragón; entre otros argumentos, el autor — buen conocedor del virreinato del Perú- alegaba la complejidad de los asuntos indianos y sus diferencias con respeto a los de otros reinos, lo cual hacía más necesario aun el conocimiento directo del territorio. Buena prueba de ello era, a su juicio, que de las 70 u 80 cédulas anuales que se despachaban a Indias, tan solo una décima parte fueran «de cosas decididas, las demás son para consultar y querer S. M. ser informado, diciendo "por cuanto a nuestra noticia ha venido [...] mandamos a la audiencia nos avise del estado de [...]"». La experiencia, pues, considerada como «el nivel por el cual las cosas de estado se rigen», ${ }^{7}$ era esencial en un Consejo como el Indias, cuyas ocupaciones en materia de gobierno y guerra eran bastante más frecuentes que las de justicia.

Desde la propia sala del Consejo, en 1630 el conde de Puebla — como presidente- aconsejaba que en sustitución de Juan de Palafox fuera nombrado como fiscal del Consejo Francisco de Alfaro, precisamente porque venía de ser oidor en Lima, alegando que «este sujeto es entre todos los que pueden ofrecerse el de mayor experiencia y aprobación porque ha servido muchos años en las Indias y ha sido asesor de los virreyes y visitado personalmente todas las provincias del Perú, con particulares observaciones de lo que ha menester aquel gobierno». ${ }^{8}$ Casi 20 años después, Solórzano Pereira en su Política Indiana dejaba testimonio de que

se ha tratado muchas veces, y tenido por conveniente (aunque no con resolución precisa de ejecutarlo) que en el Supremo Consejo de las Indias haya de ordinario algunos consejeros que sean naturales de ellas, o por lo menos hayan servido tantos años en sus audiencias, que puedan haber adquirido entera noticia de todas sus materias y particularidades, y darla a los demás compañeros, cuando los casos la pidan [... como] lo

7 Consideraciones sobre si conviene, o no, que los consejeros del Real de Indias en esta corte sean de los que han servido en las Audiencias de ellas, British Library (BL), Add MS 13992, 25-33. Aunque anónimo, sin fecha y sin lugar, del propio memorial se desprende que fue escrito en Perú; en cuanto a su autoría, el estilo, la letra, las fuentes y la forma de argumentar la exposición apuntan hacia Solórzano Pereira, lo cual dataría el texto antes de 1628.

8 Consulta sobre la sustitución de Juan de Palafox como fiscal del Consejo, Madrid, 18 de enero de 1630, AGI, Indiferente General, 756. 
que vemos se hace y practica en los Consejos de Aragón, Italia y Portugal, que nunca se dan si no a naturales de sus provincias, o a ministros que hayan servido en ellas. ${ }^{9}$

Aunque no hay en las Ordenanzas del Consejo de 1636 ninguna indicación sobre los requisitos que debían reunir los consejeros de Indias, ${ }^{10}$ una consulta elevada al rey el 11 de mayo de 1676 no deja lugar a dudas sobre el consenso existente al respecto entre los miembros de la Cámara de Indias, ${ }^{11}$ quedando finamente recogido este criterio en el decreto de reforma del Consejo promulgado el 6 de julio de 1677, en el que se hace constar explícitamente:

y porque conviene que los consejeros tengan práctica y experiencia de aquellas provincias, he mandado a la Cámara de Castilla que para la provisión de estas ocho plazas se me consulten sujetos que hayan servido en los tribunales de las Indias y especialmente a los que en conformidad de mis órdenes hubieren sido promovidos y servido ya algún tiempo en los de España. ${ }^{12}$

El decreto ratificaba, por lo tanto, el tradicional principio de promoción que debía marcar el cursus honorum de los magistrados, ${ }^{13}$ quienes deberían ir ascendiendo en cargos y destinos desde las instancias inferiores en las plazas menos apetecidas a los niveles más altos en las audiencias de mayor prestigio para, eventualmente, acabar accediendo a los consejos de la corte. El problema era que ese principio de promoción tampoco se cumplía.

Un repaso a la relación de consejeros de Indias pone de manifiesto que la participación de individuos con experiencia americana fue muy escasa a lo largo del siglo XVII. De los 209 individuos que ejercieron como

9 Solórzano, 1648, Libro V, cap. XV, 896-897.

10 Moranchel Pocaterra, 2001 y 2002.

11 «habiendo servido estos mismos sujetos [magistrados que han servido en América] en las chancillerías y audiencias de Castilla serían muy a propósito para cualquiera de los consejos y particularmente para el de Indias por las noticias que habrían adquirido del gobierno municipal de ellas [...] Y esto se verifica bien con lo que se practica en los de Aragón, Italia y Flandes [...] Y esto se ha calificado bastantemente siempre que ha venido en el Consejo ministros que han estado en las Indias y últimamente se reconoció con la asistencia del Lic. D. Juan de Villela que fue presidente del Consejo, Alonso Maldonado de Torres, D. Rodrigo de Aguiar, D. Juan de Solórzano y D. Bartolomé Morquecho que fueron del dicho Consejo». Resolución de la Cámara, 22 de diciembre de 1676: «Dese aviso de esta resolución a los virreyes para que la participen a los oidores de las Audiencias de Lima y México». Consulta proponiendo el medio para nombrar a los mejores sujetos en las plazas de las audiencias americanas, Madrid, 11 de mayo de 1676, AGI, Indiferente General, 785.

12 Decreto de reforma del Consejo de Indias, Madrid, 6 de julio de 1677, AGI, Indiferente General, 287.

13 Sobre el concepto de cursus honorum de los letrados, su discurso e ideología, véase Barrientos, 2004. 
presidentes y consejeros de Indias en ese siglo, tan solo 15 (7 \%) habían estado alguna vez en América, y solo 40 tenían experiencia en asuntos indianos por haber sido previamente fiscales del Consejo de Indias. La concentración de magistrados con conocimiento directo de América fue especialmente llamativa entre 1600 y $1630,{ }^{14}$ posiblemente como consecuencia de las ideas reformistas introducidas por el duque de Lerma y el conde de Lemos en la gestión de los asuntos americanos. Fue entonces cuando ocuparon sus plazas dos de los consejeros más reputados de cuantos ejercieron en el siglo XVII: Rodrigo de Aguiar y Acuña y Juan de Solórzano Pereira. Precisamente por ser ambos tan conocidos y sus obras tan consultadas, proyectan una idea un tanto distorsionada sobre la presencia de magistrados con experiencia americana, ya que suelen ser citados como ejemplos de dicha participación, cuando más bien deberían ser mentados como excepciones de una práctica consolidada. En todo caso, ambos juristas fueron extraordinariamente importantes en la historia del Derecho indiano, y más concretamente en el tema que nos ocupará más adelante, cual es la reivindicación de la posición que las Indias debían ocupar en la Monarquía Hispánica en relación a los otros reinos que la componían.

Si el Consejo de Indias era favorable a la promoción de magistrados procedentes de América ¿quién se oponía? y ¿cómo se explica su escasa incorporación al Consejo? La clave de esa aparente contradicción podría encontrarse en la intensa - y recurrente- polémica mantenida entre las Cámaras de Castilla y de Indias al respecto. Veamos un caso.

En abril de 1652 la Cámara de Indias elevó una consulta sobre la petición de una plaza de consejero realizada por Martín de Arriola, por entonces presidente de la Audiencia de Quito y con 24 años de servicio en tierras americanas. Pese al informe favorable de la Cámara de Indias, el rey —asesorado por la de Castilla, a quien recordemos competía la materia- denegó la petición alegando:

que tiene graves inconvenientes el abrir la puerta a las consecuencias de traer plazas de los tribunales de esta corte a los que sirven en las audiencias de las Indias [...] mayormente cuando hay en [las chancillerías de la península] sujetos muy aprobados y beneméritos de 5, 10,12 y 14 años, por no haber lugar de traerlos a la corte, a quien

14 Cuando ejercen como presidente Luis de Velasco, marqués de Salinas (1610-1617), y como consejeros Eugenio de Salazar (1600-1602), Juan Roco de Villagutierre Chumacero (16011610), Francisco Alonso de Villagra (1604-1607), Rodrigo de Aguiar y Acuña (1604-1629), Alonso Maldonado de Torres (1604/1612-1628), Juan de Villela (1612-1618), Juan Fernández de Boán (16131615), Juan de Solórzano Pereira (1629-1644). Véase Schäfer, 2003 [1935], v. 1, apéndice I; Barrientos, 2000 . 
causaría sumo desconsuelo verse pospuestos y que a estos en conciencia no se deben anteponer los que sirvieren en las Indias, a donde tienen mayores comodidades. ${ }^{15}$

Frente a esa reticencia de la Cámara de Castilla al regreso de los magistrados destinados en América, la de Indias argumentó que:

no se niega su razón a los que sirven a VM en estos reinos para ser antepuestos en las plazas de la corte y otras competentes a que suelen salir, pero [...] tal vez se acuerde la Cámara de Castilla de los que están sirviendo a VM en las Indias, pues no deben excluirse por eso de sus esperanzas de volver a su naturaleza los que procedieren como deben, sin echar raíces por allá, ni desconfiarse de esto otros premios en partes tan remotas y ocasionadas donde si fuera posible se habían de enviar los mejores sujetos, lo cual se conseguirá mucho menos juzgando que sólo pasan a morir fuera de sus patrias, casas y deudos. ${ }^{16}$

Queda claro, en todo caso, que fue la Cámara de Castilla quien se opuso a trasladar de regreso a la península a los ministros destinados en Indias — posiblemente para conservar para sí ese espacio de patrocinioy que el rey aceptó su criterio frente al defendido por la Cámara de Indias. Analizada la cuestión con detenimiento, parece evidente que la Cámara de Castilla —en el caso concreto de Martín de Arriola — desvió la atención de la cuestión principal mezclando jerarquías: en las consultas elevadas al rey presenta el caso como si se tratara de un oidor (como los de Granada o Valladolid) que pide ser trasladado al Consejo de Indias, pero Arriola era presidente de una audiencia, y por lo tanto su posición no era equivalente a la de los oidores en Castilla. ${ }^{17} \mathrm{El}$ argumento de la Cámara de Castilla solo tendría fundamento si los oidores de las chancillerías tuvieran un rango equivalente al de presidente de una audiencia en América, pero no era ese el caso, y así lo hace constar la Cámara de Indias el 22 de noviembre de 1652 al decir «y que aunque es lo regular venir algunos de aquellos ministros a las chancillerías de Valladolid y Granada han sido los que no tenían más grado que de oidores de Lima y México, pero tiene diferente consideración los que están sirviendo en presidencias actuales». ${ }^{18}$

15 Consulta de la Cámara sobre petición de Martín de Arriola de una plaza de consejero de Indias, Madrid, 2 de septiembre de 1652, AGI, Quito, 2, 588 y ss.

16 Consulta de la Cámara sobre petición de Martín de Arriola de una plaza de consejero de Indias, Madrid, 22 de noviembre de 1652, AGI, Quito, 2, 605.

17 La misma situación se planteó en 1699 con Mateo Mata Ponce de León, presidente de la Audiencia de Quito, quien no tuvo por ascenso la plaza que se le ofrecía en Valladolid y prefirió jubilarse como oidor en Lima. Véase Ponce Leiva, 2013, 358.

18 Consulta de la Cámara sobre petición de Martín de Arriola de una plaza de consejero de Indias, Madrid, 22 de noviembre de 1652, AGI, Quito, 2, 605. 
En diciembre de 1652 el rey comunicó a la Cámara de Indias la decisión adoptada por la de Castilla, según la cual Martín de Arriola debía viajar a España y «a vista de ojos se decidirá». La respuesta ante lo que se consideró una innecesaria dilación del asunto se centró en tres puntos: 1) que no hacía falta hacerle venir de América, ya que con los informes enviados era suficiente; 2) «que es muy perjudicial hacerle venir sin tener certeza en el nombramiento, o peor aún nombrarle solo porque está aquí»; y 3) «que los presidentes no pueden abandonar sus puestos para venir a pretender a la corte, que no es normal dejar sus plazas sin motivo justificado y menos aún para pretender». Por otra parte, dado que el interesado solo pedía licencia si se le confirmaba la plaza, la Cámara de Indias no se pronunció sobre el permiso hasta que no se solventara el asunto de su plaza. ${ }^{19}$ Finalmente se dio permiso a Martín de Arriola para regresar a España cuando se produjera una vacante, pero no llegó a hacerlo ya que murió en 1651, es decir un año antes del debate entre Cámaras. ${ }^{20}$

La consulta de 1652 citada en relación al caso Arriola plantea una cuestión bastante más amplia que la relativa a una plaza de consejero de Indias, ya que extendía el problema a todas las audiencias de la España peninsular, no solo a los consejos de la corte. En la segunda mitad del siglo XVII era el propio Consejo de Indias quien constataba la escasa circulación de magistrados entre ambas orillas de la Monarquía Hispánica al decir «la experiencia ha mostrado han sido muy pocos los que han vuelto a España». Por eso, en 1676 volvió a proponer que se adjudicasen dos plazas de oidores en las Chancillerías de Valladolid y Granada y otras dos en las Audiencias de Sevilla y Galicia para que ascendieran a ellas los oidores que estuvieran sirviendo en Lima y México («pues los demás se supone tienen ascensos a ellas»), de manera que «trayendo las experiencias y calificación que les daría su buen proceder y habiendo servido estos mismos sujetos en las chancillerías y audiencias de Castilla serían muy a propósito para cualquiera de los consejos y particularmente para el de Indias». La reina gobernadora aceptó la propuesta, pero excluyendo las plazas en Galicia y en Sevilla «y a esta última tendría inconveniente en proveerlos por las dependencias que traerían de las Indias». ${ }^{21}$

19 Consulta de la Cámara sobre petición de Martín de Arriola de una plaza de consejero de Indias, Madrid, 26 de diciembre de 1652, AGI, Quito, 2, 617.

20 Consulta de la Cámara sobre nombramiento de presidente de Quito, Madrid, 23 de diciembre de 1653, AGI, Quito, 2, 683.

21 Consulta proponiendo el medio para nombrar a los mejores sujetos en las plazas de las audiencias americanas, Madrid, 11 de mayo de 1676, AGI, Indiferente General, 785. 
De acuerdo con lo dispuesto en mayo de 1676, entre enero y febrero de 1677 la Cámara de Indias propuso el nombramiento de varios oidores de Lima y México como magistrados en las audiencias castellanas o como jueces letrados de la Casa de Contratación, pero a mediados de 1677 aun no se habían expedido los títulos correspondientes, por lo que la Cámara de Indias volvió a solicitar al rey que instara a la Cámara de Castilla que empezara cuanto antes a poner en práctica la resolución, máxime teniendo en cuenta la inminente partida de la flota y los galeones y que convenía difundir la noticia lo antes posible por América, «pues con esto se alentarán los ministros de Indias a proceder con mayor desvelo en el cumplimiento de sus obligaciones». ${ }^{22}$ Queda así planteada la estrecha relación existente entre la promoción efectiva de los magistrados destinados en América y su recto proceder en el cumplimiento de sus funciones.

Para comprobar si se cumplió o no ese principio de promoción de magistrados con experiencia americana en las chancillerías o en los consejos de la península, a continuación se presentan los resultados de un estudio realizado a partir del seguimiento de las carreras administrativas de 86 letrados como fiscales, oidores o presidentes en el virreinato peruano entre 1598 y 1700 . Se deja, pues, el ámbito del Consejo de Indias para considerar en exclusiva a los letrados que ejercieron en determinadas audiencias indianas. El punto de conexión entre los individuos considerados es que en algún momento de su vida fueron nombrados para ejercer en la Audiencia de Quito; ahora bien, teniendo en cuenta que prácticamente todos los que llegaron a tomar posesión del cargo en Quito ejercieron antes o después en Lima, Charcas o Santa Fe, la muestra constituye un grupo representativo de magistrados con experiencia en el área andina, ya que esos 86 individuos suponen un tercio del total (277) de cuantos que ejercieron en las cuatro audiencias contempladas. ${ }^{23}$

De los datos recopilados se desprende que la imagen de un constante trasiego de agentes de un punto a otro de la Monarquía Hispánica puede ser válida para los cargos de gobierno y militares, ${ }^{24}$ pero no lo es en absoluto en la judicatura. El seguimiento preciso de las trayectorias profesionales de

22 Consulta sobre lo que conviene que la Cámara de Castilla empiece a poner en práctica la resolución de consultar una plaza en las chancillerías castellanas para ministros indianos, Madrid, 27 de abril de 1677, AGI, Indiferente General, 785.

23 La principal fuente de información han sido las consultas y decretos sobre nombramientos en la Audiencia de Quito en AGI, Quito, 2-5, 102, 106. También Schäfer, 2003 [1935]; Barrientos, 2000; Burkholder y Chandler, 1982.

24 Véase Centenero de Arce, 2012. 
los 86 letrados considerados permite constatar su escasa circulación intercontinental ya que, como reiteradamente expone la documentación, los que iban a América no regresaban a la península; de hecho, de los 57 peninsulares que llegaron a tomar posesión de su cargo en el área andina, sabemos el lugar de fallecimiento de 43, de los cuales solo cuatro murieron en la España peninsular. Paradójicamente, murieron más americanos en la península - sin ejercer en ella cargo alguno- que peninsulares previamente destinados en América. Este fenómeno resulta particularmente interesante para establecer una comparación con el caso del imperio portugués, donde efectivamente se produce una intensa y fluida circulación de magistrados entre los diversos tribunales de Portugal, África, América y Asia. ${ }^{25}$

Yendo un poco más allá, algunos casos que podrían presentarse como evidencias de una amplia circulación de agentes a lo largo y ancho de la Monarquía Hispánica comprobamos que, en realidad, obedecían a dos situaciones un tanto irregulares. La primera era el producto de una negociación entre el Consejo y el candidato elegido para un determinado cargo, estableciéndose un compromiso por ambas partes: el letrado aceptaba un destino poco grato (por ejemplo visitador en Filipinas) a cambio de ser recompensado después con otro más amable (oidor en Guatemala). ${ }^{26} \mathrm{La}$ segunda eran los conocidos traslados «en depósito», situación poco deseada tanto por el Consejo como por los letrados ya que era un claro indicador de que el desplazado había tenido problemas en su anterior destino. Cabe destacar, por otro lado, que los magistrados promovidos desde América no necesariamente procedían de Lima o México, como recomendaban las consultas del Consejo y aprobó el rey, sino que llegaron también desde Quito, La Plata, Guadalajara y Guatemala.

Estrechando más aun el espacio contemplado, vemos que ni siquiera se produjo la supuesta circulación de agentes por la propia América, como se ha deducido a partir de algunos casos de virreyes que pasaron de Nueva España a Perú. Hubo, efectivamente, una intensa circulación pero con una clara especialización regional, o virreinal; en el caso de los presidentes, oidores y fiscales, al llegar a Panamá o Santo Domingo siguieron normalmente un itinerario que les llevó de Panamá a Santa Fe, de ahí a Quito, a Charcas y a Lima, sin pasar al virreinato de Nueva España. De hecho, solo hemos encontrado siete casos de letrados que ejercieron en ambos

25 Véase al respecto Camarinhas, 2009 (92) y, más ampliamente, 2010.

26 Consulta sobre nombramiento de Jerónimo Ortiz de Zapata como visitador de Filipinas, Madrid, 9 de octubre de 1630, AGI, Quito, 2, 35. 
virreinatos, siendo la mayoría oidores que pasaron de Lima a México o viceversa, pero no entre las demás audiencias. Esta diferencia entre lo supuesto y lo constatado es un nuevo indicador de la distorsión que suele provocar tomar como representativo del conjunto de América lo que se produce tan solo en las capitales virreinales.

El irregular cumplimiento del principio de promoción tuvo negativas consecuencias en la gestión de América. La cadena de problemas comenzaba con la dificultad de reclutar letrados para servir en las audiencias americanas; dada la certeza de que, como se ha indicado anteriormente, «sólo pasan a morir fuera de sus patrias, casas y deudos», ${ }^{27}$ los recién nombrados alegaban situaciones de la más diversa índole que les impedían ocupar la plaza - especialmente una alarmante falta de salud entre sus familiares_,${ }^{28}$ hasta el punto de que en 1660 el gobernador del Consejo de Indias, José González Caballero, se vio en la obligación de recordar que las órdenes del rey debían cumplirse, pues no eran opcionales. ${ }^{29}$ Esta dificultad en el reclutamiento produjo un desequilibrio entre lo deseable y lo posible en materia de nombramientos; en opinión del Consejo, «no queriendo pasar a las Indias los sujetos beneméritos es preciso que las plazas de las audiencias vengan a recaer en otros de menos letras y grados que no habiendo podido lograr su pretensión en estos reinos, la necesidad les obliga a apetecer las plazas de Indias». Todo ello desembocó, finalmente, en un incremento de las prácticas arbitrarias e irregulares que subyacen en el llamado «mal gobierno»; en una consulta de 1676 el Consejo estimaba que las Indias estaban

gobernadas por ministros que no tienen las partes necesarias para administrar justicia [...] ocasionándose de esto y de la codicia de los ministros tantos y tan graves daños [...] Y es cierto que esto ha muchos años que se padece en ellas y que el Consejo lo tiene entendido y $[\ldots]$ lo ha procurado remediar [...] No es bastante remedio el de las visitas generales y particulares. ${ }^{30}$

El recorrido trazado desde lo que parecía ser un asunto meramente administrativo —el sistema de promoción entre agentes destinados en Indias - hasta llegar a un severo y recurrente problema que debió afrontar la

27 Consulta de la Cámara sobre petición de Martín de Arriola de una plaza de consejero de Indias, Madrid, 22 de noviembre de 1652, AGI, Quito, 2, 605.

28 Carta de Antonio Genil Santaelices a José González, gobernador del Consejo de Indias, rechazando su nombramiento como presidente de Quito, Madrid, 24 de julio de 1660, AGI, Quito, 3, 36.

29 Consulta del gobernador del Consejo de Indias, sobre las dificultadas para cubrir la plaza de presidente de la Audiencia de Quito, Madrid, 28 de agosto de 1660, AGI, Quito, 3, 30.

30 Consulta proponiendo el medio para nombrar a los mejores sujetos en las plazas de las audiencias americanas, Madrid, 11 de mayo de 1676, AGI, Indiferente General, 785. 
Monarquía Hispánica — como era la corrupción— pone de manifiesto la necesidad de contemplar las cuestiones americanas y europeas desde una perspectiva conjunta, que evidencie la conexiones entre lo que se hacía en un lado y lo que provocaba en el otro, pero guardando las especificidades de cada ámbito territorial, ya que la situación observada en el Consejo de Indias no era la misma que en los otros consejos de la monarquía. Frente a la consideración de que la corrupción en América fue mayor que en la España peninsular y se debía a la insaciable ambición de sus élites, a la inmadurez de las instituciones implantadas o a la aceptación tácita de la corrupción por parte del público en general, ${ }^{31}$ con una visión ciertamente más crítica el Consejo de Indias en 1676 centró la cuestión en dos aspectos que le competían directamente: la recta administración de justicia — «siendo así que esta es la que más conserva los reinos y provincias»—y el recto proceder de sus agentes, para lo cual «el principal remedio es enviar buenos ministros a las audiencias». ${ }^{32}$ Otra posibilidad era buscar en la propia América los candidatos idóneos, pero esa opción parece no haber sido contemplada, como se verá a continuación.

\section{Reivindicaciones americanas: el (interminable) debate en torno a los nombramientos}

Es bien conocida la existencia de una larga tradición reivindicativa de los americanos específicamente dedicada a su participación, o mejor dicho a su exclusión, de la alta administración hispana. La documentación al respecto es inequívoca en cuanto a la enorme importancia conferida por los coetáneos al lugar de origen de aquellos que eran objeto de mercedes, fueran estas de cargos o de honores.

Entre 1620 y 1670 cabe situar el punto álgido de la polémica, siendo entonces cuando la reivindicación de los cargos públicos para los españoles nacidos en Indias se convierte en un asunto central de la ensayística hispanoamericana. Un repaso a la cronología en que los principales autores en la materia publicaron sus obras lo confirma plenamente: entre los pioneros se encuentra Zapata Sandoval (1609), y a él se remiten sin excepción Ortiz de Cervantes (1619), Salinas y Córdoba (1630), Gaspar de Villarroel

31 Sobre el debate actual en torno a la corrupción en la Monarquía Hispánica véase Alberro, 2000; Dedieu, 2000; Lomnitz-Adler, 2000; Bertrand, 2013; Ponce Leiva, 2016.

32 Consulta proponiendo el medio para nombrar a los mejores sujetos en las plazas de las audiencias americanas, Madrid, 11 de mayo de 1676, AGI, Indiferente General, 785. 
(1631-1634 [1663], 1656, 1661), Bethancurt y Figueroa (1637), Bustamante (1640), Solórzano Pereira (1647), Solórzano Velasco (1652) y Bolívar de la Redonda (1667), entre otros muchos. Sus obras forman un conjunto de textos estrechamente relacionados entre sí, cuyo objetivo esencial fue defender el derecho de prelación que los americanos debían tener sobre los cargos y oficios de Indias; para ello recurrieron tanto a los fundamentos que jurídicamente les amparaban como a los méritos personales acumulados por varias generaciones. ${ }^{33}$

No se analizará a continuación cómo los americanos fueron paulatinamente superando cualquier obstáculo que les fuera surgiendo (básicamente a través del uso del dinero y de las relaciones familiares); tampoco interesa ahora el desenlace final de ese largo conflicto. Lo que interesa es el debate en sí mismo, por sus implicaciones intelectuales y por su vinculación con la teoría y la práctica política en la Monarquía Hispánica.

La cuestión nuclear planteada en estas obras guarda relación, en última instancia, con un debate mucho más amplio en torno a las formas de incorporación, o agregación, de los diferentes reinos a la monarquía y las consecuencias políticas que de ello se derivan. Lo que se dirime, entre otras cosas, es la relevancia y la presencia que debía tener en el gobierno de la monarquía la impronta americana.

\section{Constatación del fenómeno: americanos en la judicatura}

Para aclarar de qué estamos hablando cuando nos referimos a escasa participación de americanos en la alta administración de justicia parece conveniente ofrecer algunos datos concretos. Frente a los 15 consejeros que ejercieron en el siglo XVII habiendo pasado previamente por América —-sobre un total de 209-, la presencia en el Consejo de individuos nacidos y criados en América se reduce a dos casos: Francisco Guevara Altamirano y Juan Jiménez de Montalvo y Saravia. ${ }^{34}$

33 Sobre los principios mantenidos por estos autores y sus líneas de argumentación existe una amplísima literatura. A título orientativo véase Lavallé, 1982; Ponce Leiva, 1997; Garriga Acosta, 2003.

34 Francisco Guevara Altamirano: Puebla de los Ángeles, c. 1606 - España, padre y madre mexicanos, formado en Salamanca, nombrado consejero en 1654. Juan Jiménez de Montalvo y Saravia: Lima, c. 1621 - Madrid, 1685, hijo de oidor en Lima y madre chilena, formado en Salamanca y nombrado consejero en 1679. No se incluye en este cómputo a Diego González de Contreras, consejero de Indias en 1624, quien nació en Lima por ser su padre oidor allí, pero su vida transcurrió en España, donde llegó a ser consejero de Castilla. Véase Barrientos, 2000. 
El ejercicio de americanos en las audiencias indianas como fiscales, oidores o presidentes fue notablemente más alto que en el Consejo de Indias, pero es necesario tener en cuenta una serie de variables para comprender cómo y bajo qué condiciones se desarrolló su ingreso en los tribunales. Retomando el conjunto de los 86 letrados contemplados en este estudio, comprobamos que 57 fueron peninsulares y 25 americanos, quedando un resto de 4 de los cuales no constan datos; la ya conocida mayoría de magistrados peninsulares en las audiencias americanas queda, por lo tanto, plenamente constatada. La cronología de esa incorporación se inicia en la década de 1640 y tiene su punto álgido entre 1670 y 1690, lo cual confirma la lenta y en general tardía presencia de americanos en la judicatura, a diferencia de su amplia participación en la esfera local, en la real hacienda y en menor proporción en los corregimientos. Como ya se observó en el caso de los consejeros, esta es una cuestión que claramente diferencia a la América hispana de la portuguesa, donde la presencia de letrados brasileños en tribunales fue muy amplia; alguna relación debe de tener esta participación con el hecho de todos ellos se formaran en Coimbra, dado que en Brasil no había universidades.

Al considerar la vía de acceso a los cargos conviene poner especial atención a la práctica seguida, no solo a la norma, para así poder establecer la vía precisa de nombramiento: además de contemplar la diferencia entre decreto y consulta, ${ }^{35}$ cabe precisar las variantes que presentan ambos sistemas. De los 86 letrados considerados, sabemos la vía de acceso al cargo desempeñado en Quito en el $69 \%$ casos, entre los cuales resulta evidente el predominio de la vía consultiva (un $59 \%$ sobre el total, pero un $86,4 \%$ sobre los casos conocidos), frente al $9 \%$ sobre el total (o 13,6\% sobre los casos conocidos) que representan los nombramientos por decreto; cabe concluir, por lo tanto, que durante el siglo XVII prevalece la vía consultiva. Sin embargo, un análisis detenido del contenido de las consultas permite observar que el sistema de nombramiento por consulta se fue haciendo cada vez más opaco, en el que cada vez intervenían menos consejeros -inclusive dentro de la misma Cámara de Indias-, los cuales fueron argumentando cada vez menos sus decisiones, hasta convertir la consulta en una escueta terna, cuya lógica a veces no solo no resulta clara, sino incluso sospechosa.

Cruzando el lugar de origen con la vía de acceso, constatamos que: a) el porcentaje de magistrados peninsulares es más del doble que el de

35 La vía del decreto, por ser una orden directa del rey al Consejo, fue el sistema utilizado para hacer ejecutiva una venta o concesión real no sujeta a la valoración de los méritos del candidato. 
americanos (66 \% frente a $29 \%$ ); b) el porcentaje de magistrados peninsulares nombrados por consulta es tres veces superior al de americanos que acceden por la misma vía (46\% frente a $15 \%) ;{ }^{36}$ y c) el porcentaje de americanos que ingresa por decreto (por dote o por compra) es el doble que el presentado por los peninsulares (6\% frente a 3,6\%).

Las cifras globales pueden ser bajas, pero la tendencia es clara y representativa. No puede ser casualidad que esta cuestión —es decir las reivindicaciones de los americanos sobre cargos en la alta administración y muy especialmente en la administración de justicia — pierda protagonismo en la literatura americana a partir de la década de 1670, momento en el que la venta de cargos se convierte en la vía mayoritaria de acceso a la administración. Ante esa evidencia, continuar escribiendo y publicando obras sobre la materia resultaría a todas luces inútil; la incorporación de americanos a la administración de justicia no se produjo, por lo tanto, por un éxito de sus reivindicaciones sobre la prelación a la que aspiraban, sino por el predominio del sistema de compra en todos los cargos y oficios de la administración, única vía de acceso efectiva para los españoles nacidos en Indias. La cuestión volvería a resurgir con mayor fuerza si cabe en el siglo XVIII, ${ }^{37}$ precisamente cuando arreció la llegada de agentes peninsulares y las reformas borbónicas intentaron neutralizar el pacto hasta entonces mantenido entre las élites americanas y la Corona.

\section{Argumentos desde la metrópoli}

Conocemos bien las opiniones de los americanos al respecto y el despliegue de argumentos presentados, pero ¿qué se decía en la España peninsular al respecto? Hasta el momento, no puedo citar una obra escrita en la península dedicada específicamente a rebatir las tesis americanas. De forma dispersa aparece el argumento de que América era parte agregada de forma «accesoria» por conquista a Castilla, y por tanto los americanos no tenían ningún derecho de prelación, como podía ocurrir en otros reinos incorporados a la Corona aeque pincipaliter ${ }^{38}$ también se alude, aquí y allá, al hecho de que estaban emparentados con los residentes en su distrito

36 De los 57 peninsulares 38 fueron elegidos por consulta (46,6\%); de los 25 americanos lo fueron $13(15,8 \%)$

37 Véase Garriga Acosta, 2002; y para el caso portugués Slemian, 2014.

38 Sobre las diferencias entre ambas vías de incorporación de reinos a una unidad mayor y, especialmente, sobre las consecuencias de ellas derivadas para los vasallos, véase Gil Pujol, 2012. 
(entre otros, con aquellos peninsulares que habían sido nombrados por no estar emparentados).

Sí contamos, por el contrario, con documentación explícita en relación al nombramiento de americanos en el Consejo de Indias a través de un informe emitido por el secretario de Estado en 1635, cuyo contenido resulta muy significativo sobre la opinión que parece haber imperado en la corte. Seguramente como consecuencia de una consulta del Consejo de Indias al rey, en abril de 1635 Jerónimo de Villanueva ${ }^{39}$ dio su parecer en relación a «la pretensión que tienen los naturales de la Indias, llamados criollos, de que uno de ellos sea de ordinario consejero», ${ }^{40}$ pretensión que el rey se inclinaba a considerar favorablemente «por los ejemplares de los Consejos de Aragón, Italia y Portugal». En principio, Villanueva se mostró favorable a incluir algún americano en el Consejo de Indias, pero consideró que tal posibilidad no debería convertirse en norma recurriendo, entre otros, a los siguientes argumentos:

1. «Podría ser que alguna vez faltase de quien echar mano y si muriese el que ocupase esta plaza, primero que se hallase otro de aquellas provincias tan remotas, pasarían muchos años». Al margen de que para evitar esas situaciones existían las relaciones de méritos enviadas regularmente al Consejo, una vez más aparece la distancia como argumento - o como pretexto- utilizado con frecuencia para encaminar las decisiones en el rumbo que interesara.

2. «Siendo las mismas provincias tantas y tan dilatadas [...] qué consuelo han de recibir en que se les dé por premio a sus hijos una sola plaza en este Consejo, pues estrechar esto a que sea de esta o aquella provincia, es agraviar y aun irritar a las otras». Es decir, que para no agraviar a ningún americano, según Villanueva era mejor nombrar a un peninsular.

3. «También se peligra en que el que viniere ha de tener muchos parientes». Es esta una cuestión que aparece reiteradamente asociada a los americanos, como si los letrados nacidos en la metrópoli no tuvieran (o contrajeran) parentesco alguno.

39 Jerónimo de Villanueva, secretario de Estado y protonotario de Aragón fue estrecho colaborador del conde-duque de Olivares, ocupándose de la «tesorería de gastos secretos desde 1627 hasta su encarcelamiento y caída en desgracia en 1643», véase Gil Martínez, 2016. Miembro (capa y espada) de la Cámara de Indias entre 1644 y 1647, pasó todo ese tiempo preso por la Inquisición; murió en 1653. Schäfer, 2003, I, 343.

40 Consulta del secretario de Estado, Jerónimo de Villanueva, sobre reserva de una plaza de consejero de Indias a un criollo, Madrid, 28 de abril de 1635, Archivo General de Simancas (AGS), Estado, 2655.37. 
4. «Que el ejemplo de Aragón e Italia no parece se ajusta, pues estos reinos se unieron como ellos estaban, equi [sic] principaliter, lo que no pasó en las Indias, pues se rigen por las leyes de Castilla». Este es el argumento de mayor peso, ya que es el único con respaldo jurídico. En la documentación se observa una clara inclinación del rey a considerar las Indias como territorios si no aforados, al menos agregados a la monarquía en similares condiciones a los otros reinos, cuestión a la que se opone Villanueva apelando a la diferencia existente entre reinos agregados aeque principaliter y aquellos incorporados de forma «accesoria». Trasladada esta cuestión al ámbito de la provisión de oficios significa que al considerar a las Indias como parte de Castilla, teóricamente sus súbditos deberían tener los mismos derechos al margen de que fueran de Nueva España o de Valladolid - por ser todos ellos castellanos por naturaleza-, cosa que como hemos visto no ocurría. Aun cuando no se aceptara el derecho de prelación tan vivamente defendido por los americanos ${ }^{41}$ ello no implicaba necesariamente su exclusión de la alta administración castellana.

5. «Que no se consiguen con proveer un criollo las noticias generales de las Indias, porque raras veces las tienen de más que de las provincias donde nacieron». Al parecer Villanueva consideraba preferible un letrado que tuviera la ventaja de desconocer por igual cualquier territorio americano, frente a otro que al menos conociera uno.

«Esto se consigue con más cierta prevención con la atención de proveer los sujetos de más partes que suele haber en las audiencias de Lima o México, aunque no sean criollos». En definitiva, Villanueva recurrió al consabido premio y consideración a los magistrados con experiencia americana cuando, como ya se ha visto, tampoco ellos fueron promocionados.

La abundancia, extensión, erudición y cuidado en la argumentación que presentan las obras escritas por los americanos en relación al mecanismo de provisión de cargos son, por sí mismas, indicadores de la importancia que los coetáneos otorgaban al tema. Frente a ellas, llama la atención la simpleza de las consideraciones alegadas por un personaje tan influyente - y tan cercano al valido y al rey- como era el secretario de Estado Villanueva, que claramente intentó minimizar la cuestión. Es más, el argumento empleado en 1652 por la Cámara de Castilla para oponerse al nombramiento de Martín de Arriola como consejero, parece indicar que la reticencia a incorporar individuos procedentes de América obedecía más bien al interés

41 Véase Garriga Acosta, 2003. 
de los consejeros de Castilla en conservar un espacio de patrocinio donde situar a quienes resultase conveniente.

Dando un salto en el tiempo, que permite constatar la vigencia del tema a lo largo de los siglos y la importancia que tuvo en la construcción y conservación de la monarquía, nos situamos a mediados del siglo XVIII, cuando surgen «nuevas propuestas en relación a la política de nombramientos al servicio de las tareas de construcción nacional, que algunos vislumbran ya como imperiosas», ${ }^{42}$ lo cual no implicó que se dejaran de vender cargos de justicia y gobierno en América, como es bien sabido. ${ }^{43}$ Una de esas propuestas de cambio se presentó en 1768 en el Consejo Extraordinario que se había formado — como sala especial del Consejo de Castilla tras la crisis de 1766 - para deliberar sobre las medidas convenientes para sosegar el descontento que la expulsión de los jesuitas había causado en México. Los fiscales Campomanes y Moñino creían que para «prevenir el espíritu de independencia y aristocracia» que percibían, se hacía preciso adoptar medidas que fomentasen el «amor a la matriz que es España», formando de este modo un «cuerpo unido de Nación». ${ }^{44}$ En esta línea, una de las medidas más urgentes era implementar, precisamente, la igualdad o reciprocidad en la política de nombramientos, esto es:

guardar la política de enviar siempre españoles a Indias con los principales cargos, Obispados y Prebendas, y colocar en los equivalentes puestos de España a los criollos [...] esto es lo que estrecharía la amistad y unión, y formaría un solo cuerpo de Nación, siendo los criollos que aquí hubiese, otro tanto número de rehenes para retener aquellos países bajo el suave dominio de S.M. ${ }^{45}$

Como puede apreciarse en una perspectiva de larga duración, la cuestión tuvo un amplio recorrido. Los asesores del rey fueron plenamente conscientes de la importancia que el tema tenía en la cohesión y conservación de la monarquía, pero no por ello se avanzó en su resolución. En realidad, el panorama fue a peor.

42 Garriga Acosta, 2002, 800.

43 Véase, entre la extensa bibliografía al respecto publicada por este autor, Andújar Castillo, 2008. Sobre la compra de plazas de consejero de Indias durante el reinado de Felipe V: Burgos Lejonagoitia, 2015, cap. 5.

44 Consulta de Campomanes y Moñino como fiscales del Consejo Extraordinario, Sala especial del Consejo de Castilla, Madrid, 5 de marzo de 1768. Citada por Garriga Acosta, 2002, 800. Véase también Konetzke, 1950, 45-47.

45 Garriga Acosta, 2002, 800. 


\section{Negociando posiciones: integración, emulación y preeminencias}

\section{¿Por qué son tan importantes los nombramientos?}

Las frecuentes reclamaciones de los americanos en relación a su marginación de la alta administración, o a su aspiración de formar parte de ella, no es la manifestación de un mero conflicto de intereses susceptible de ser neutralizado con los habituales matrimonios y negocios entre españoles americanos y los llegados de la metrópoli, como ha sido frecuentemente considerado y, en consecuencia, relegado a un segundo plano, cabe decir de índole doméstica.

No se trata de presentar una lista de agravios desde una visión victimista, pero tampoco parece aceptable — por insuficiente — la visión pragmática y economicista del tema que atiende esencialmente a los beneficios materiales pretendidos u obtenidos. Desde la perspectiva americana, nos encontramos ante una cuestión que al menos desde comienzos del siglo XVII adoptó un cariz de claro contenido político e ideológico; no solo se estaba dirimiendo el papel de los americanos en la monarquía, sino su percepción por los otros reinos que la componían. ${ }^{46}$ La cuestión, en definitiva, era cómo se sentían los americanos en ese edificio, construido con una argamasa tan rígida como flexible, y cómo eran valorados por los demás reinos.

Desde el punto de vista de la percepción de los coetáneos, como ha explicado Gil Pujol, es evidente «la tendencia de todos los reinos de la monarquía a equipararse entre sí en cuanto a prerrogativas e inmunidades»; hay, por lo tanto, una «inquietud de todos los reinos por autoafirmarse ante su rey y ante los restantes territorios». ${ }^{47}$ Se trata, pues, de un asunto eminentemente político y cultural que está presente en todos los reinos de la Monarquía Hispánica y que tiene que ver con la posición que cada uno ocupa en el conjunto de esa monarquía, las bases sobre las que se sustentan las relaciones entre rey y reino, y la inquietud de todos los reinos por afirmarse ante su rey y ante los restantes territorios. Ahí radica la importancia de las reivindicaciones americanas: en su afán de emulación y autoafirmación.

Si bien desde el punto de vista de la teoría política «en el conjunto de la Monarquía, Portugal es quizá el ejemplo más clásico de agregación [y]

46 Como expuso el quiteño fray Gaspar de Villarroel, capellán de la Capilla Real en Madrid y obispo de Chile, «es un sambenito portátil para una provincia decir que no hay capaces ministros dentro de ella. No hay cosa que a un país pueda avergonzarle más». Villarroel, 1661, 364.

47 Gil Pujol, 2012, 79. 
las Indias Occidentales lo son de integración», ${ }^{48}$ desde la perspectiva que ofrece la interpretación que del asunto hicieron los juristas esa dicotomía no resulta tan evidente. En una época en la que las prácticas de gobierno y justicia no venían tan marcadas por las leyes cuanto por la interpretación que de tales leyes hacían los juristas, resulta significativo que letrados implicados en la gestión de la América hispana utilizaran diferentes términos para describir el tipo de vínculo que unía a Castilla con sus posesiones americanas. En esa línea, como sutilmente observa Gil Pujol, «para quien quisiera creerlo, se iba imponiendo el supuesto - más o menos fundadode que los distintos reinos de la monarquía compartían una parecida condición aeque pincipaliter ${ }^{49} \mathrm{o}$, en última instancia, que a los ojos de algunos juristas y virreyes el lugar adjudicado a las Indias en el conjunto de la monarquía debía ser algo más que un territorio ocupado por conquista. Dando la vuelta a la argumentación, Solórzano Pereira sostuvo reiteradamente que las Indias no eran menos que los otros reinos por haber sido incorporadas «accesoriamente», sino iguales a ellos por ser parte de Castilla; ${ }^{50}$ yendo más allá, Aguiar y Acuña defendió la mayor consideración que se había de tener con los territorios conquistados, por ser su mérito superior al de los heredados, «que procede por ventura y es ganancia sin propia virtud». ${ }^{51}$

Como conclusión de este largo debate sobre la posición que ocupaban las Indias en el conjunto de la Monarquía Hispánica podría decirse que su situación era de carácter mixto o, quizás, mejor dicho, incompleto: de las características que definían a los territorios aforados, las Indias cumplían el tener un Consejo soberano y particular en la corte, el tener una legislación propia - además de la castellana-, el contar con tribunales territoriales capaces de aplicar la normativa real, el haber creado una jurisprudencia propia en sus territorios, el tener capacidad de resolver los procesos en su ámbito jurisdiccional; por el contrario los requisitos que las Indias no cumplían

48 Mazín Gómez y Ruiz Ibáñez, 2012, 30.

49 Gil Pujol, 2012, 83. Así parece entenderlo Aguiar y Acuña cuando afirma «después de unidos unos reinos y otros a una corona no se halla razón natural ni jurídica para que importe algo haberse agregado el más antiguo por conquista (Indias) y el menos por herencia (Flandes)». Copia de consulta a S.M. representado las razones que le asisten para que no le prefiera el de Flandes. Hizola el Sr. D. Rodrigo de Aguiar y Acuña y es de su letra, Madrid, 22 de diciembre de 1628, BL, Egerton, 348, 74-76, cita en $74 \mathrm{r}$.

50 «Los reinos y provincias que accesoriamente se unen o incorporan con otros se tienen y juzgan por una misma cosa, y se gobiernan por las mismas leyes y gozan de los mismos privilegios que el reino a quien se agregan», Solórzano, 1676 [1629], 380.

51 Copia de consulta a S.M. representando las razones [...] Aguiar y Acuña, 1628, BL, Egerton, 348, 74v. 
- o lo hacían de forma muy esporádica — eran el tener magistrados naturales de sus territorios, el gozar de derecho de prelación en los cargos y el contar con naturales de esos reinos en las casas de la reina y del rey. ${ }^{52}$

Las diferentes cuestiones que se han venido presentado en las páginas anteriores, como el sistema de promoción en la judicatura, la presencia de consejeros con experiencia americana, la participación en la alta administración de justicia de los españoles nacidos en Indias y la posición que América debía ocupar en el conjunto de la monarquía confluyen en el Consejo de Indias en las décadas de 1620 y 1630, periodo en el que se llevan a cabo importantes proyectos de reforma en los asuntos indianos; ${ }^{53}$ mientras en Perú se escribían las influyente obras de Ortiz de Cervantes (1619), Salinas y Córdoba (1630) y Gaspar de Villarroel (1631-1634), en la corte se planteó la necesidad de revisar en profundidad la situación en las Indias - lo que dio lugar a una cadena de visitas - y se puso en práctica la política iniciada por el conde de Lemos tendente a nombrar consejeros con experiencia previa en asuntos de Indias, práctica que, como vimos, duró poco. Es entonces cuando tuvo lugar el conocido enfrentamiento entre el Consejo de Flandes y el de Indias por una cuestión — significativamente- de precedencias y honores. Se trata de una cuestión puntual y aparentemente superflua, pero representativa de los temas que venimos analizando y altamente simbólica.

\section{El imperio de las Indias frente al condado de Flandes}

Los conflictos jurisdiccionales fueron algo habitual en la administración polisinodial hispánica, dado el solapamiento de competencias entre consejos territoriales y no territoriales. En el caso específico del de Indias, las interferencias más frecuentes se dieron con el de Castilla (siendo proverbiales las malas relaciones que mantuvieron ambos), con el de Hacienda, con el de Estado y ocasionalmente con el de Portugal.

La disputa que enfrentó al Consejo de Indias y al de Flandes en 1628, como veremos a continuación, no se enmarca en esa danza de órdenes, apelaciones, contraórdenes o ratificaciones que dio movimiento y ritmo a la gestión administrativa. No fue un conflicto jurisdiccional al uso. Fue más bien un exponente del debate sobre cuáles eran las prioridades políticas del momento, sobre la primacía de los intereses dinásticos frente al de los

52 Sobre las características atribuidas a los reinos aforados véase Cardim, 2016.

53 Amadori, 2013. 
reinos y, sobre cuál era la posición adjudicada a América y a los americanos en el conjunto de la monarquía. ${ }^{54}$ Partimos, por lo tanto, del reconocimiento entre los coetáneos de una identificación entre consejos y territorios por ellos «representados», en la línea sostenida por Solórzano Pereira al afirmar: «la calidad y preeminencia de los Consejos y magistrados se mira y regula por la de los reinos y estados que gobiernan y representan». ${ }^{55}$

Para entender lo que ocurrió en 1628 parece necesario remontarse unos años atrás. La muerte sin descendencia del archiduque Alberto de Austria (1621), esposo y primo de la infanta Isabel Clara Eugenia, a quienes Felipe II había otorgado como dote (1598) los Países Bajos reservándose para sí y sus herederos el emblemático ducado de Borgoña, supuso el fracaso del intento de establecer allí una rama autóctona de los Austrias; los Países Bajos volvieron entonces al dominio del rey de España, quedando la infanta como gobernadora hasta su muerte en 1633. Al estar gobernados por un miembro de la familia real, esos territorios no habían tenido su correspondiente consejo en la corte, pero esa situación cambio al quedar instaurado un nuevo Consejo de Flandes en 1627. ${ }^{56}$ Pues bien, el detonante del enfrentamiento entre consejos fue la pretensión del flamenco (o mejor dicho la voluntad real por motivos dinásticos) de tener primacía frente al de Indias en la jerarquía polisinodial, lo cual implicaba su preeminencia en los actos públicos, entre ellos la ceremonia del besamanos real con motivo de la pascua de Navidad en 1628, que desató el escándalo.

El primer mensaje enviado al Consejo de Indias sobre los cambios que se avecinaban llegó en el lenguaje de gestos propio de la corte; el 24 de julio de 1628, con motivo de la visita del príncipe de Gales, a los consejeros de Indias se les notificó que debían ceder a «otras personas» los lugares que tradicionalmente ocupaban en las ventanas de la plaza Mayor. Ante su inmediata $-\mathrm{y}$ previsible — protesta, la respuesta real fue un tranquilizador recado de que para la próxima fiesta «ya era tarde, pero lo tendré en cuenta». ${ }^{57}$ Un año después, inmerso ya en el conflicto de preeminencias, en dos consultas del 20 y 21 de junio de 1629, tanto el duque de Medina de las

54 Sobre la disputa mantenida entre el Consejo de Indias y el de Flandes, véase Barrios, 2002; Mazín Gómez, 2012. Entre los reinos europeos se dieron también conflictos de precedencia, concretamente entre el Consejo de Italia y el de Portugal. Véase BL, Egerton, 348.

55 Solórzano, 1676 [1629], 365. Véase al respecto Gil Pujol, 2004, 52-54.

56 Esteban Estríngana, 2005, cap. I.

57 Queja del presidente del Consejo de Indias, duque de Medina de la Torres, por habérseles privado a los consejeros de las ventanas en la plaza Mayor para ver las fiestas, Madrid, 24 de julio de 1628, AGI, Indiferente General, 756. 
Torres como el Consejo en pleno volvieron a reclamar el lugar público que les correspondía, solicitando al rey «se sirva de mandar se señale ventanas al Consejo de Flandes en otra parte, y que no se quiten al Consejo de Indias las que tienen tanto años ha [...] y más no hallándose hoy en la corte los consejeros de Flandes»; la respuesta real fue «así lo he mandado» y «quedo advertido», dando por zanjada la cuestión. ${ }^{58}$

Entre ambos episodios simbólicamente escenificados en los balcones de la plaza Mayor de Madrid, en el seno del Consejo se elaboraron varias consultas y memoriales que constituyen el alegato oficial presentado ante la — mal recibida y peor acatada — pretensión del de Flandes. La primera consulta fue redactada por Rodrigo de Aguiar y Acuña el 22 de diciembre de $1628 ;^{59}$ en ella condensa, muy ajustadamente, los argumentos jurídicos que avalaban la prioridad que debían tener las Indias frente a Flandes, siendo la base sobre la que se desarrollaron las siguientes consultas y memoriales, los cuales, con mayor o menor detenimiento, incorporan todas las consideraciones alegadas en esta primera consulta. ${ }^{60}$

La prelación de Indias sobre Flandes se fundamenta, entonces, no solo en que formaba parte inalienable de la Corona de Castilla, sino en que su incorporación fue anterior a la de Flandes, y a partir de ahí «no se halla razón natural ni jurídica para que importe» la vía por la cual se había producido la unión. En cuanto a la antigüedad de los consejos, «el de Flandes es tan moderno en estos reinos, que hoy es el primer día que trata de que se le conceda besamano, y se quiere anteponer a quien la ha besado a cuatro reyes». Las Indias eran, o habían sido, «imperios poderosísimos de emperadores y monarcas de inmensos señoríos y de sumas riquezas»; así, la enormidad de las Indias — donde «en una sola de sus islas, de las más pequeñas, cabría todo Flandes»—-era solo comparable a su riqueza y «siendo la plata y el oro los nervios de la guerra [...] cosa es que no se puede dejar de sentir en aquellas provincias que sea inferior la que da, que la que recibe, la que paga que la que consume». Tras rebatir la prelación de la varonía frente a la herencia

58 Consulta del duque de Medina de las Torres sobre disputa entre el Consejo de Indias y el de Flandes por las ventanas de la plaza mayor, Madrid, 20 de junio de 1629, AGI, Indiferente General, 756. Consulta sobre disputa entre el Consejo de Indias y el de Flandes por las ventanas de la plaza mayor, Madrid, 21 de junio de 1629, AGI, Indiferente General, 756.

59 Rodrigo Aguiar y Acuña (1571-1629), fue oidor en Quito entre 1598 y 1604. Nombrado consejero de Indias en 1604, cuando Solórzano Pereira se incorpora al Consejo como fiscal en 1627, Aguiar y Acuña lleva 25 años como consejero, siendo por entonces el más antiguo. Barrientos, 2000, 69, Schäfer 2003 [1935], 340. ton, 348 .

60 Copia de consulta a S.M. representado las razones... Aguiar y Acuña, 1628, BL, Eger- 
materna — dado que a Felipe IV todos sus reinos le fueron transmitidos por línea paterna-, Aguiar y Acuña recuerda que «es más glorioso el conquistar que el heredar [...] con tantos peligros, tantas vidas de los naturales, tanta sangre derramada del reino que conquista». Completa este argumento la consideración de que «conquistar es agregar y ensanchar los términos y la potencia [...] siendo unos mismos los vasallos y la misma gente que desde los principios de la conquista nacieren en aquellas provincias hijos de los conquistadores son verdaderos descendientes de los godos como nosotros». Estas alusiones a los súbditos americanos — que no se encuentran en los memoriales y consultas posteriores - resultan especialmente significativas ya que permiten a Aguiar introducir en el alegato el componente específicamente americano - como son los naturales - y a la vez defender la igualdad de los españoles nacidos en Indias en relación a los nacidos en la España peninsular.

Dejando para otra ocasión un análisis más detenido de las consultas y memoriales elaborados en torno a este debate, de momento cabe destacar la evidente continuidad — en ideas, argumentación y frases textuales - entre la consulta de Aguiar y Acuña del 22 de diciembre de 1628 y la obra publicada por Solórzano en 1629, compuesta por 20 razones avaladas por un centenar de notas que acreditan la conocida erudición de su autor; el punto de conexión entre ambas sería un memorial anónimo y sin fecha dividido en 11 puntos, cuya autoría puede atribuirse a Solórzano, y que seguramente fue redactado a fines de 1628 o principios de $1629 .{ }^{61}$ Todo ello formó parte de una estrategia diseñada desde el Consejo de Indias consistente en preparar una sólida argumentación, solicitar que el de Flandes presentara por escrito «las causas en que se funda», y esperar el momento oportuno para presentar el caso ante el rey, una vez atendidos «otros cuidados que se debían anteponer». ${ }^{62}$

No sabemos si el Consejo de Flandes llegó a elaborar el memorial solicitado, aunque se conoce bien su línea argumental al ser rebatida en la documentación generada por el de Indias, pero lo que resulta evidente es que al final prevaleció el criterio dinástico frente a cualquier otra consideración. Si en la Monarquía Hispánica todo se integraba en un orden y este tenía una jerarquía interna, por muy incorporadas que estuvieran a Castilla, en esa

61 Memorial al rey sobre que el Consejo Real de las Indias ha de preferir al Consejo de Flandes..., s.1. / s.f. [1628], BL, Egerton, 348, 77-81.

62 Consulta sobre la precedencia del Consejo de Flandes frente al de Indias, Madrid, 18 de febrero de 1629, AGI, Indiferente General, 756. 
jerarquía las Indias ocupaban el último lugar. Desconocemos el impacto que esta polémica pudo tener entre los súbditos americanos, incluso si la noticia llegó a cruzar el mar, pero el tiempo acabo resolviendo el conflicto: la riqueza de las Indias entró en el escenario de la corte por la puerta que abrió la venalidad en las últimas décadas del siglo XVII, mientras Flandes dejo de formar parte de la Monarquía Hispánica tras los acuerdos de Utrech en 1714.

\section{Conclusiones}

La existencia de una intensa circulación de agentes de la administración por los diferentes reinos de la Monarquía Hispánica es un fenómeno ampliamente mentado por la bibliografía reciente. Si es eso lo que se busca, sin duda se encontrará. Cabe tener en cuenta, sin embargo, que tal circulación no afectó por igual a todos los reinos y a todas las jurisdicciones. Según los datos recopilados en el presente texto a partir de fuentes primarias, en el ámbito específico de la judicatura indiana se constata una escasa circulación intercontinental, una clara especialización por virreinatos (del Perú y de Nueva España) y una mínima presencia de españoles nacidos en América, tanto en cuanto se refiere al Consejo de Indias como a la judicatura en general.

Teniendo en cuenta que los consejeros de Indias eran designados por la Cámara de Castilla, la llamativa escasez de nombramientos de individuos con experiencia en tierras americanas se debería, posiblemente, al interés del rey o de los camaristas en reservar para sí un espacio de patrocinio, que no siempre guardó relación con los méritos de los candidatos y el natural transcurrir de los cursus honorum. La escasa presencia de americanos en la judicatura podría atribuirse bien al hecho de que no gozasen del derecho de prelación (por no ser territorios aforados), bien a la prohibición de que los jueces ejercieran en los distritos de donde eran naturales; al respecto cabría considerar, por un lado, que la no prelación no implicaba necesariamente la exclusión y, por otro, que la prohibición de naturaleza afectaba exclusivamente a la población de origen, no al conjunto de América.

¿Cómo explicar entonces la escasa participación de americanos en la alta administración hispana? Más que una falta de voluntad política, o un indicador del «desprecio» con que eran vistos los súbditos americanos en la corte - como alegaron algunos coetáneos mostrando su profundo 
malestar-, más bien podría atribuirse a la práctica generaliza del clientelismo y a la potencia del patrocinio; de ahí el recurrente énfasis hecho en la justicia distributiva y en las nefastas consecuencias de la acepción de personas. Esa práctica intensiva del patrocinio, entendido por algunos como parte del sistema y por lo tanto plenamente aceptable, fue interpretada por otros ya entonces como un peligro para la recta administración de justicia y la adecuada selección de los agentes reales; no es tanto que se tuvieran prejuicios contra los americanos - no entraremos en ese laberinto- cuanto que se tenía mucho a favor de los allegados. Por eso las ventas de cargos y honores tienen, desde la perspectiva americana, una lectura muy distinta a la hecha desde la España peninsular.

La conflictiva relación entre los españoles nacidos en Indias y la alta administración - la única que premia y da lustre a los súbditos - guarda relación con un debate mucho más amplio en torno a la integración de las Indias en Castilla y a la posición que debían ocupar en el conjunto de la Monarquía Hispánica. Lejos de ser un lugar común, de irrelevantes consecuencias prácticas, requiere ser entendido desde una perspectiva más global, que no esté ni enfocada únicamente al análisis de los intereses económicos de las élites locales, ni exclusivamente centrada en América, sino integrada en el amplio mundo hispánico; eso sí, sin olvidar la peculiar situación que las Indias ocupaban en el entramado político y administrativo de tal escenario.

Las diferentes formas de incorporación de los reinos a la Monarquía Hispánica, y las consecuencias de ellas derivadas, constituyeron otro frente de debate entre juristas que no quedó en absoluto zanjado por disposiciones legales y argumentos de teoría política, sino más bien resuelto por el contundente pragmatismo de la «razón de estado». De los argumentos esgrimidos por unos y otros, a la vista de los resultados obtenidos cabe concluir —en contra de lo que esperado- que la incorporación de las Indias a la Corona de Castilla no favoreció precisamente su integración en la Monarquía Hispánica, más bien todo lo contrario; al ser considerado un territorio no aforado e incorporado por conquista, no se le reconoció una personalidad histórica y jurídica propia, quedando en una posición vulnerable frente a los otros reinos.

En definitiva, tanto la participación de los españoles de Indias en la administración, como la vía de incorporación de estas a la Monarquía fueron temas emblemáticos de la ensayística hispanoamericana, que guardan estrecha relación entre sí y constituyen un rito de paso inevitable para comprender el significado de términos de alto contenido político como son 
«emulación», «autoafirmación» y «percepción» propia o ajena. Una plaza no era solo un cargo que permitía medrar en la jerarquía social, era también (o sobre todo) un lugar concreto y adecuado en un mundo enorme, complejo e implacable. En un tiempo regido por las posiciones y los símbolos, cuando cada gesto tenía su significado y sus consecuencias, una afrenta al Consejo de Indias significó —o así pudo interpretarse — una afrenta al territorio que dicho Consejo representaba en la corte, patria común de todos los súbditos.

Recibido el 8 de enero de 2016 Segunda versión 24 de mayo de 2016 Aceptado el 25 de julio de 2016

\section{Referencias bibliográficas}

Alberro, Solange, «Control de la Iglesia y transgresiones eclesiásticas durante el periodo colonial», en Lomnitz-Adler, C., Vicios públicos, virtudes privadas: la corrupción en México, México, CIESAS, 2000, 33-47.

Altolaguirre, Ángel de (ed.), Colección de las Memorias o Relaciones que escribieron los Virreyes del Perú acerca del estado en que dejaban las cosas generales del Reino, Tomo II, Madrid, Imprenta Mujeres Españolas, 1930.

Andújar Castillo, Francisco, Necesidad y venalidad: España e Indias, 1704-1711, Madrid, Centro de Estudios Políticos y Constitucionales, 2008.

Amadori, Arrigo, Negociando la obediencia: gestión y reforma de los virreinatos americanos en tiempos del conde-duque de Olivares (1621-1643), Madrid/ Sevilla, CSIC / Universidad de Sevilla / Diputación de Sevilla, 2013.

Barrientos Grandón, Javier, Guía prosopográfica de la judicatura letrada indiana (1503-1898), Madrid, Fundación Histórica Tavera, 2000.

Barrientos Grandón, Javier, «El Cursus de la Jurisdicción Letrada en las Indias (s. XVI -XVII)», en Barrios Pintado, F. (coord.), El gobierno de un mundo. Virreinatos y Audiencias en la América Hispánica, Cuenca, Universidad de Castilla-La Mancha, 2004, 633-708.

Beltrán y Rózpide, Ricardo (ed.), Colección de las Memorias o Relaciones que escribieron los Virreyes del Perú acerca del estado en que dejaban las cosas generales del Reino, Tomo I, Madrid, Sociedad de Historia Hispano-Americana, 1921.

Bertrand, Michel, «Viejas preguntas, nuevos enfoques: la corrupción en la administración colonial española», en Andújar, F. y Felices de la Fuente, M. M. (eds.), El poder del dinero. Ventas de cargos y honores en el Antiguo Régimen, Madrid, Biblioteca Nueva, 2013, 46-62. 
Burgos Lejonagoitia, Guillermo, Gobernar las Indias. Venalidad y méritos en la provisión de cargos americanos, 1701-1746, Almería, Universidad de Almería, 2015.

Burkholder, Mark A. y Chandler, D. S., Biographical Dictionary of Audiencia Ministers in the Americas, 1687-1821, Westport (Conn.), Greenwood Press, 1982.

Camarinhas, Nuno, «O aparelho judicial ultramarino português. O caso do Brasil (1620-1800)», Almanack braziliense, 9, São Paulo, 2009, 84-102.

Camarinhas, Nuno, Juízes e administração da justiça no Antigo Regime. Portugal e o império colonial, séculos XVII e XVIII, Lisboa, Fundação Calouste Gulbenkian, 2010.

Cardim, Pedro, «As Cortes de Portugal e o governo dos "territórios ultramarinos" (séculos XVI-XVII)», en Xavier, Â. Barreto y Silva, C. Nogueira da (orgs.), O governo dos Outros. Poder e Diferença no Império Português, Lisboa, Imprensa de Ciências Sociais, 2016, 437-466.

Centenero de Arce, Domingo, «¿Una monarquía de lazos débiles? Circulación y experiencia como formas de construcción de la Monarquía Católica», en Pardo Molero, J. F. y Lomas Cortés, M. (coords.), Oficiales reales: los ministros de la Monarquía Católica: siglos XVI-XVII, Valencia, Universitat de València, 2012, 137-161.

Dedieu, Jean-Pierre, «Procesos y redes. La historia de las instituciones administrativas de la época moderna, hoy», en Castellano, J. L.; Dedieu, J.-P. y López-Cordón, M. V. (eds.), La pluma, la mitra y la espada. Estudios de historia institucional en la Edad Moderna, Madrid, Marcial Pons, 2000, 13-30.

Esteban Estríngana, Alicia, Madrid y Bruselas. Relaciones de gobierno en la etapa postarchiducal (1621-1634), Lovaina, Leuven University Press, 2005.

Garriga Acosta, Carlos A., «Los límites del reformismo borbónico: a propósito de la administración de la justicia en Indias», en Barrios Pintado, F. (coord.), Derecho y Administración Pública en las Indias Hispánicas. Actas del XII Congreso Internacional de Historia del Derecho Indiano, Cuenca, Universidad de Castilla-La Mancha, 2002, vol. I, 781-822.

Garriga Acosta, Carlos A., «El Derecho de Prelación: en torno a la construcción jurídica de la identidad criolla», en González Vales, L. E. (coord.), XIII Congreso del Instituto Internacional de Historia del Derecho Indiano. Actas y estudios, San Juan de Puerto Rico, Asamblea Legislativa de Puerto Rico, 2003, vol. 2, 1085-1128.

Gil Martínez, Francisco, «Ingresos venales, gastos cortesanos. El discurso de la monarquía sobre la venalidad y la construcción del Buen Retiro», en Ponce Leiva, P. y Andújar Castillo, F. (eds.), Mérito, venalidad y corrupción en España y América. Siglos XVII y XVIII, Valencia, Albatros, 2016, 157-172.

Gil Pujol, Xavier, «Un rey, una fe, muchas naciones. Patria y nación en la España de los siglos XVI y XVII», en Álvarez-Ossorio, A. y García García, B. J. (eds.), 
La Monarquía de las naciones. Patria, nación y naturaleza en la Monarquía de España, Madrid, Fundación Carlos de Amberes, 2004, 39-76.

Gil Pujol, Xavier, «Integrar un mundo. Dinámicas de agregación y de cohesión en la Monarquía de España», en Mazín, O. y Ruiz Ibáñez, J. J. (eds.), Las Indias Occidentales. Procesos de incorporación territorial a las Monarquías Ibéricas, México, El Colegio de México, 2012, 69-108.

Konetzke, Richard, «La condición legal de los criollos y las causas de la independencia», Estudios Americanos, II, 5, Sevilla, 1950, 31-54.

Lavallé, Bernard, Recherches sur l'apparition de la conscience créole dans la vice-royauté du Perou: l'antagonisme hispano-créole dans les ordres religieux (XVIème-XVIIème siècles), Bordeaux, Atelier National de Reproduction des Thèses, Université de Lille III, 1982, 2 vols.

Lomnitz-Adler, Claudio, «Introducción», en Lomnitz-Adler, C. (coord.), Vicios públicos, virtudes privadas: la corrupción en México, México, CIESAS, 2000, 11-30.

Mazín Gómez, Óscar, «El lugar de las Indias occidentales en la Monarquía española del siglo XVII», en Dobado González, R. y Calderón Fernández, A. (coords.), Pintura de los Reinos. Identidades compartidas en el mundo hispánico. Miradas varias, siglos XVI-XIX, México, Fomento Cultural Banamex, 2012, 175-185.

Mazín Gómez, Óscar y Ruiz Ibáñez, José Javier, «Estudio Introductorio», en Mazín, O. y Ruiz Ibáñez, J. J. (eds.), Las Indias Occidentales. Procesos de incorporación territorial a las Monarquías Ibéricas, México, El Colegio de México, 2012, 7-40.

Moranchel Pocaterra, Mariana, «Las Ordenanzas del Real y Supremo Consejo de Indias de 1636. Primera Parte», Cuadernos de Historia del Derecho, 8, Madrid, 2001, 273-379.

Moranchel Pocaterra, Mariana, «Las Ordenanzas del Real y Supremo Consejo de Indias de 1636. Parte Segunda», Cuadernos de Historia del Derecho, 9, Madrid, 2002, 247-364.

Ponce Leiva, Pilar, «El poder del discurso o el discurso del poder: el criollismo quiteño en el siglo XVII», Procesos, 10, Quito, 1997, 3-20.

Ponce Leiva, Pilar, «El valor de los méritos. Teoría y práctica política en la provisión de oficios (Quito, 1675-1700)», Revista de Indias, LXXIII-258, Madrid, 2013, 341-364.

Ponce Leiva, Pilar, «Percepciones sobre la corrupción en la Monarquía Hispánica, siglos XVII y XVIII», en Ponce Leiva, P. y Andújar Castillo, F. (eds.), Mérito, venalidad y corrupción en España y América. Siglos XVII y XVIII, Valencia, Albatros, 2016, 193-212.

Schäfer, Ernesto, El Consejo Real y Supremo de las Indias: su historia, organización y labor administrativa hasta la terminación de la Casa de Austria,

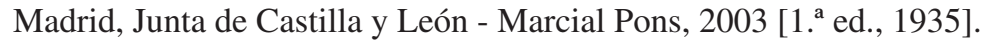


Slemian, Andréa, «A primeira das virtudes: justiça e reformismo ilustrado na América portuguesa face à espanhola», Revista Complutense de Historia de América, 40, Madrid, 2014, 69-92.

Solórzano Pereira, Juan, Política Indiana, Madrid, Diego Díaz de la Carrera, 1648.

Solórzano Pereira, Juan, «Memorial y discurso de las razones que se ofrecen para que el Real y Supremo Consejo de las Indias deba preceder en todos los actos públicos al que llaman de Flandres» [1629], en Obras posthumas. Recopilación de vanos tratados, memoriales y papeles, escritos algunos en causas fiscales, y llenos todos ellos de mucha enseñanza y erudición, Zaragoza, Herederos de Diego Dormer, 1676, 351-397.

Soria Mesa, Enrique, «Family, Burocracy and the Crown. The Wedding Market as a Form of Integration among Spanish Elites in the Early Modern Period», en Cardim, P.; Herzog, T.; Ruiz Ibáñez, J. J. y Sabatini, G. (eds.), Polycentric Monarchies. How did Early Modern Spain and Portugal Achieve and Maintain a Global Hegemony?, Brighton-Portland, Sussex Academic Press, 2012, 73-81.

Villarroel, Fray Gaspar de, Primera parte de los comentarios, dificultades y discursos literales, morales y místicos obre los evangelios de los domingos de adviento y todos los del año, Madrid, Domingo García Morrás, 1661. 